\title{
Implementation of National Drug Policy in Different Countries: An Appraisal and Experience from Bangladesh
}

\author{
FR CHOWDHURY ${ }^{\mathrm{a}}$, MS BARI ${ }^{\mathrm{b}}$, MI KHAN ${ }^{\mathrm{c}}$
}

(J Bangladesh Coll Phys Surg 2011; 29: 177-179)

Key Words: National Drug Policy, World Health Organization, Bangladesh.

In May 1975, the then director general of World Health Organization (WHO) Dr Halfdan Mahler, strongly advocated at the World Health Assembly (WHA) for the development of national pharmaceutical policies based on the affordability, quality and availability of drugs. A resolution was passed which urged the Secretariat of WHO to help Member States to formulate national pharmaceutical policies that meet the actual health needs of the people. The resolution introduced the concepts of 'essential drugs' and 'national drug policy (NDP)' so far the global public health is concerned. Bangladesh is one of those countries who responded early to that call and formulated their NDP in $1982^{1}$. The 1982 policy hugely benefited the pharmaceutical industry of Bangladesh and helped the entrepreneurs to develop this sector with good quality and standard. Bangladesh is now exporting drugs in more than fifty countries of the world with good reputation after completely mitigating the local demands. Not only in Bangladesh, after implementation of drug policy under WHO guidance, India now ranks 13th in world production by value and ranks 4th in the

a. Dr. Fazle Rabbi Chowdhury, MSc. (Tropical \& Infectious Dis, UK), Registrar, Department of Medicine, Sylhet M.A.G.Osmani Medical College, Sylhet, Bangladesh.

b. Dr. Md. Shafiqul Bari, FCPS ( Medicine), Associate Professor, Department of Medicine, Sylhet M.A.G.Osmani Medical College, Sylhet, Bangladesh.

c. Prof Dr Md Ismail Khan, MBBS, M phil, GDHPEd(Aus), Vice Principal and Head, Dept of Pharmacology, Dhaka Medical College, Dean, Faculty of Medicine, University of Dhaka

Address of Correspondence: Dr. Fazle Rabbi Chowdhury, MSc. (Tropical \& Infectious Dis, UK), Registrar, Department of Medicine, Sylhet M.A.G.Osmani Medical College, Sylhet, Bangladesh., Cell: 01916578699, Email: mastershakil@hotmail.com volume of pharmaceuticals produced ${ }^{2}$. Now there are 20000 pharmaceutical manufacturers in India ${ }^{2}$. Most of the vaccines are now produced in India. Countries like Brazil, Egypt, Turkey, Indonesia etc. are now producing both active ingredients and finished products. This is a great achievement for their pharmaceutical sector $^{2}$. By 1999, 66 countries had formulated or updated a NDP within the previous 10 years, compared with 14 countries in $1989^{2}$. To date approximately 156 countries have formulated their own NDP² . W.H.O guidelines suggest three broad objectives of drug policy: accessibility, quality, safety \& efficacy of drug and finally rational use. In this appraisal the case of Bangladesh which has 27 years experience of its drug policy will be used as an example to evaluate the pitfalls of implementation of those objectives comparing some other developing countries.

Accessibility: The main objective of the Bangladesh NDP was to ensure that every people can get the essential and necessary drugs easily with affordable price. With this end in view 150 'essential drugs' were identified in the drug policy (1982) of Bangladesh with controlled pricing $^{3}$. This list has been reduced to 117 in the year $1993^{3}$. The maximum retail price of the essential drugs was fixed by the drug administration authority though the real scenario is different. Prices of essential medicines are not consistent with each other. There is wide variation of the price of same medicine within different brands. For example the price of each 'Ciprofloxacin (500mg)' tablet ranges from taka 5 to taka 15 (US\$ $0.7-0.22)^{2}$. It is said that the production cost of this drug is less than 2.5 taka per tablet ${ }^{3}$. So some companies are making an astonishing profit of Tk.12 (US\$ 0.17) per table. In Malaysian drug policy, the Government relies on market forces to decide the price of the 'essential drug', rather than controlling it. But this policy is now showing some discomfort too among mass people and public perception is now rising 
towards control of drug prices in Malaysia though it seems unsuccessful in Bangladesh. ${ }^{4}$ Price of medicine directly related to the accessibility. In Cameroon, a course of treatment for peptic ulcer costs almost twice the monthly wages of a government employee which is clearly unaffordable ${ }^{2}$. A study carried out in Ghana and Cambodia also highlights the huge gap between prices of generic and brand medicines ${ }^{2}$. A good number of countries do not even attempt to control medicine prices. $^{2}$ Over $40 \%$ countries have no regulation of medicine prices which is a mandatory part of WHO proposed effective NDP. This is really painful as drug is not like other commercial commodities rather it has got humanitarian value. Pharmaceutical business should be more humanitarian oriented. Pharmaceutical companies should keep in mind that medicines produced by them have direct impact on public health. They must not tag inordinate high price to their products which will in turn adversely affect the public health. Poor people naturally refrain themselves from buying very costly medicines. So, the companies must adopt a humanitarian approach in setting their profit margin. Over-pricing causes inadequate access to needed medicines in developing nations. To enhance the accessibility of drugs, companies should work hand in hand with the governments.

Quality, safety and efficacy of Drugs: At present more than 16000 different brands of drugs are available in the market of Bangladesh and these are produced by as many as 300 pharmaceutical companies. ${ }^{1}$ Only 4000 brands are tested for quality and 12 thousands are entering in the market without any test for lack of technical support and trained manpower ${ }^{1}$. Financial solvency is an important factor in this regard. This is a burning issue in many developing countries too. The drug control authority of these countries should give permission very cautiously for licensing a new drug. Moreover in many cases these drugs may be useless or ineffective and of similar nature. This also creates a favourable environment for fake, spurious, adulterated and harmful smuggled medicine to come in to the market. In 2004, Bangladesh drug testing laboratory tested 5000 samples and detected 300 drugs which are either counterfeit or of very low quality ${ }^{1}$. In 1998 it was 260 out of $5920^{1}$. 'No medicine without prescription' is strictly followed in almost all developed countries but unfortunately this practice is absent in the developing world. As a result misuse of valuable drugs including antibiotics is very common. In drug policy of every developing country, there should be clear rules and provision of a definite list of drug to be prescribed by the traditional village quacks or non-graduate practitioners to minimize the misuse of medicine. A recent WHO report on medicine stated that an estimated two-thirds of global antibiotic sales occur without any prescription, and studies in Indonesia, Pakistan and India showed that over $70 \%$ of patients were prescribed antibiotics without valid reason and among them the great majority (up to $90 \%$ ) of injections are estimated to be unnecessary ${ }^{2}$. Adverse drug reaction (ADR) and resistance to antibiotics are another two points of concern. Even in United States ADR rank among the top 10 causes of death and are estimated to cost between US\$ 30 and US\$ 130 billion each year ${ }^{2}$. For the treatment of malaria, chloroquine resistance is now established in 81 of the 92 endemic countries. ${ }^{2}$ Resistance to common antibiotics also established against gonorrhea, pneumonia and bacterial meningitis. These drug resistances not only put the individual at much greater risk of poor treatment outcomes but also put tremendous pressure over the national economy of a country. At present there are 67000 licensed drug stores in Bangladesh but practically it exceeds 0.2 million. ${ }^{1}$ There are no trained personnel in these drug shop and they do not hesitate to sell adulterated and low quality drugs for exorbitant profit. ${ }^{5}$ This malpractice is rampant in the rural areas Bangladesh where illiterate poor people are adversely affected. This is a common scenario for many developing countries too. Recently Malaysia took decisive steps to improve the consciousness of drug use among mass people by launching different motivation and awareness program which turn out to be effective. They also improve postmarketing surveillance and monitoring.

Rational Use of Drug: Irrational and inappropriate use of medicine is a global problem. Recently in Bangladesh many pharmaceutical companies launched a group of multi vitamin- multi mineral tablets for removing deficiency without consideration of local need and socio-economic condition of the country ${ }^{1}$. Bangladesh drug market is now flooded with different vitamins and herbal products imported by various distributor companies which are completely unnecessary and illegal to be marketed ${ }^{6,7}$. Physicians have to play vital role and 
responsibilities in this regard. They should be more cautious and judicious in prescribing drugs. For example, Oman have got improvement in prescribing patterns when the government established a directorate of rational use of drugs in 2000, besides national drug control authority. ${ }^{8}$ Recently in Iran, government thinking for a drug prescription control committee in each province, with a computer link to a national committee, which will evaluate all prescriptions and send an annual report to all respected physicians $^{9}$. Iranian government recently finished an experimental pilot project in two provinces and found it very effective. They are expecting to reduce the total drug cost around $10 \%$ annually by this way ${ }^{9}$.

Implementation of a national drug policy has not been paid required attention by the governments of most developing countries. Notwithstanding the fact, Bangladesh as a developing country has registered several significant progress in the field of public sector. Especially the national drug policy 1982 is a commendable step from the part of Bangladesh Government. However, still there is huge scope to make the drug policies of developing countries more effective. This paper has pointed out several aspects of implementation process of a national drug policy. Drugs regulators in developing countries should consider these aspects in implementing their drug policies. Only in this way, public health in developing countries will be ensured to a great extent.

\section{References:}

1. Chowdhury FR, Muqtadir MA, Chowdhury MA. [National drug policy of Bangladesh 1982 \& 2005-effective implementation is must for peoples will]. Bang Asiatic Soc Potrika 2007; 15(2): 297-308. Bengali.

2. Creese A, Gasman N, Mariko M. World Medicine Situation. World Health Organization (WHO); 2004. Report no: WHO/ EDM/PAR/2004.5.

3. Improving Access to Essential Pharmaceuticals. In: Health Division Document, Swedish International Development Cooperation Agency (SIDA) [online].Available at: www.sida.se/shared/jsp/download.jsp?f=HDD 2001.3\%5B1\%5D.pdf \&a=2492. Accessed January 18, 2011.

4. Baber ZU, Ibrahim M. Affordability of medicines in Malaysia - consumer perceptions. Essential Drugs Monitor 2003; 33: 18-9.

5. Chowdhury FR, Chowdhury MA, Chowdhury S. Quality, Safety and Efficacy of drug in Bangladesh: Where we are? Journal of Medicine 2005; 6(2):55-8.

6. Chowdhury FR, Rahman MM, Huq MF, Begum S. Rationality of drug uses-Its Bangladeshi perspectives. Mymensingh Med J 2006; 15(2):215-19.

7. Chowdhury FR,Ahasan HAMN,Rahman MM. National Drug policy of Bangladesh: Some Pitfalls in implementation. J Coll Physicians Surg Pak.2006; 16(5):368-70.

8. Working to improve rational use in Oman. Essential Drugs Monitor 2005; 34:2.

9. Dinarvand R. Iran: an evolving National Drug Policy. Essential Drugs Monitor 1996; 22: 9-10. 